\title{
Effects of early adolescent characteristics in circulation design for a junior high school building
}

\author{
K.P. Amelia, I. Hanom, W. Lukito \& S.N. Siregar \\ Telkom University, Bandung, Indonesia
}

\begin{abstract}
Good architecture is when data fulfills the function of a building and provides psychological comfort to its users. The function can be fulfilled by design guidelines applicable dimension standards, in this case issue raised is circulation in the building. Unique characteristics of these early adolescent can be anticipated in designs based on these characteristics, one of which was the role of circulation. This research is a qualitative descriptive study with a comparison of three selected Junior High School. The point being compared is the design decision in designing circulations for the three Junior High Schools. The early adolescent's characteristics approach in circulating design being considered good to facilitate users of the building. The design process makes psychological factors an approach in hope of achieving a match between the user's subject. This is sn an indicator of success in a design that has been successfully accommodated according to the needs of its users.
\end{abstract}

Keywords: early adolescent, characteristic, circulation design, Junior High School

\section{INTRODUCTION}

School is a place where teenagers spend their daily time to getting a formal education or socializing with friends informally. Time spent by the teenager can be said all day because it spends time generally, 6 hours every day. Good architecture is architecture that can facilitate / accommodate user activities and main function of architecture itself (Salura 2001:3) From the range of intensity of activity and use of buildings, it can be concluded the importance of the role of an architecture in accommodating the activities in the school. Another factor that influences a design decision is to consider the user of the architecture. In addition to the spatial dimensions of standards, design decisions are needed in the study of design psychology from its users.

In the context of the analysis raised, this study focuses on building users, namely students with the definition of adolescents aged 13-15 years with the category of early adolescents. Early adolescents have unique psychological character and development. According to the State Administration Agency Team, in Syfa, 2019 that the development of psychology is the changes experienced by individuals or organisms toward the level of maturity or maturity that takes place in a systematic, progressive and continuous way both concerning physical or psychological.

A design of the school is expected. In addition to being a place for student activities, there are the activities of teaching and learning, informal socialization, and many more activities student do at school. Design can help develop psychological characteristics of adolescents. A building, the elements forming its space can form/create psychological impression on its users (Caudil 1978), for example a narrow corridor and a low ceiling will create a different impression with a wide corridor and has a high ceiling. The unique characteristics of early adolescent are expected to be accommodated in the design of the junior high school building so users can feel comfortable and the spatial need can be completed. 


\section{METHOD}

This study uses a qualitative descriptive method, making comparisons based on the results of a survey conducted on three designs of Junior High School building. Analysis was conducted by referring to the type of space organization in architecture, circulation, and psychological/ psychological characteristics of early adolescents. The case study of this study was conducted sampled at 3 junior high schools in West Java and Jakarta assuming the following number of students.

Table 1. Number off peers in every study case.

\begin{tabular}{lll}
\hline Junior High School & Theory Class & Peers/Classes \\
\hline A & 12 classes & $10-15$ peers \\
B & 18 classes & $10-15$ peers \\
C & 12 classes & $10-15$ peers \\
2 & upper class & 18 peers \\
\hline
\end{tabular}

* Curriculum used: Cambridge curriculum

The survey was conducted by documenting the atmosphere of the space in the building and mapping the layout of the Junior High School Building. The analysis is done by discussing two elements in architecture in a building, which is the application of spatial organization patterns (spatial layouts) and the application of circulation patterns used in buildings design. These two points are explained in each case study to explain each of the conditions in the object. The results of the processed analysis of the survey data are then compared so that conclusions can be drawn.

\section{ANALYSIS}

Important characteristics of concept development in early adolescents, according to Santrock (2013), consist of seven concepts: abstract and idealistic; differentiated; contradiction with them self; the functioning self, real, and ideal true and false selves; and self-conscious and self-protective. In general, the characteristics of adolescents can be explained as individuals who are looking for an identity, expressive and crowd-like or hanging out with friends, even though early adolescents who are still looking for identity are sometimes unstable and often feel insecure with themselves. A good architectural design is a design that can provide psychological comfort to its users (Caudil 1978). In addition to providing an activity container with its functions, architecture can provide psychological comfort to its users, one of which is a psychological approach in design. These concepts and characters can be implemented in the design, to accommodate the characteristics of its users in school building case studies, are early teens.

According to Syfa (2019), the application of user characteristics into the space to be used as the main reference in the design as a problem-solver in the designing process are:

1. Consider the hierarchy of space based on the level of privacy/orientation-based needs.

2. Minimize the bulkhead in space, prioritizing the open-plan concept.

3. Application of open space area.

4. Categorize the room into different zone areas, thus psychologically humans will interact naturally.

These points can be implemented in building designs. There are six ordering principles according to D.K. Ching in the design process: axis, symmetry, hierarchy, datum, rhythm, and transformation. The order is a reference from the design as a whole guideline, which is then derived in spatial elements. Among other things, the organization of space and circulation in a building.

Circulation and organization in buildings are considered sufficient to represent the design of the space in Junior High School case studies. Assume that the circulation and organization of buildings 
is a part of the building where flow circulation of students and teachers in large numbers under certain conditions, and also illustrate the concept of flow circulation design of the building as a whole.

Space organization is the basic layout of a building in compiling patterns of relationships between rooms. Building design can regulate the flow of building user activity in addition to the spatial function distribution is by the basic arrangement of spatial organization. Horizontal circulation is a space that is used as a means of circulation or an intermediary space from one room to another, types of positions, materials, etc. Horizontal circulation can provide different visual sequence.

\subsection{Spatial organizations}

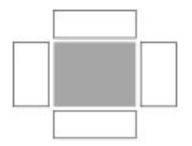

Figure 1. Radial in Case A.

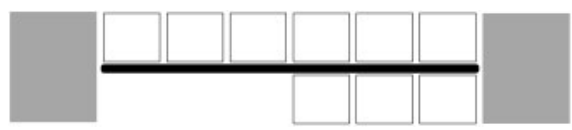

Figure 2. Linear in Case B and Case C.

Two of the three schools use radial space organizations where users are asked to be at one point first and then spread out according to the space they want to go to, but the use of linear organizations can also be used in one case study with the application of a long hallway as a reference for spatial planning. The application of spatial organization, in addition to being influenced by the concept of drafting design, is influenced by the form of the site conditions. According to building main function, it will be easier for Junior High School buildings with radial space organization, given the need for sufficient space and there is a large enough area for students to gather compared to buildings with linear space organizations.

\subsection{Horizontal circulations}

Horizontal circulation room serves as a link between the space in the school and the place of social interaction activities outside of class hours. This room is a corridor that connects space with a minimum area of $30 \%$ of the total area of the entire building and the minimum width of the corridor is $1.75 \mathrm{~m}$ (Adler 1979). Corridors that do not have walls on one side must use handlers with a height of $90 \mathrm{~cm}$ (Neufert 2000).

\subsubsection{Case A (double-loaded and linear)}

Even though the space organization was arranged radial with a fairly large lobby on the first floor of the building, Case A's classrooms were arranged linear on the first and second floors. In addition to a wide corridor aproximately $3 \mathrm{~m}$, there are voids on the 2 nd floor which also gives a broad impression. The design of the floor pattern helps to show the elevation of the floor and the difference in classrooms. Along the corridor there is a shoe storage area for students. With a wide circulation design, it provides enough space for students to move and gather and can provide additional space for students to sit along the circulation.

\subsubsection{Case B (double-loaded and radial)}

Case B classrooms are on the 2nd and 3rd floors with the application of the double-loaded corridor design. Space requirements for standing people with both of hands open width is according to the standard $1.75 \mathrm{~m}$ (Adler 1979) with linear space organization. Therefore, students can gather or carry out activities with their friends in circulation. At the ending circulation there is quite large on one side. Utilized as a public area/library, so students will prefer to gather in a larger public area/library than in the middle of the corridor. 


\subsubsection{Case C (double-, single-loaded, and radial)}

In Case $\mathrm{C}$ according to Figure 7, there is a circulation with single-loaded and double- loaded. Users are accepted in a fairly large lobby area in front of the building, so that it is then directed by the circulation that focuses on the intended space. Although there are no long corridors, two types of corridors are formed in Case C: double-loaded and single-loaded. Circulation of the double-loaded corridor is formed inside the building, after entering the user's lobby, is directed into a doubleloaded corridor. On the other side of the class there is a corridor which is directly facing the outside building, so that sunlight enters the corridor.

The use of this circulation design makes it easier to compare with the previous case, the organization of radial and double-loaded spaces that are formed giving enough space for students to have activities and users to gather. Single-loaded corridors provide a different atmosphere of the corridor that can provide comfort for building users, especially students. The use of different materials on the side that is directly related to the outer space as a treatment solution of the building from the direct sun can simultaneously provide an aesthetic element in the building.

Table 2 is a summary analysis in $\backslash$ three case studies were carried out.

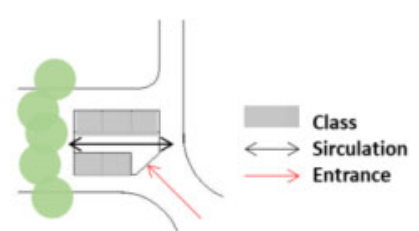

Figure 3. Layout sketch of Case A.
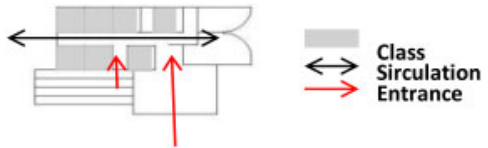

Figure 5. Sketch layout in Case.

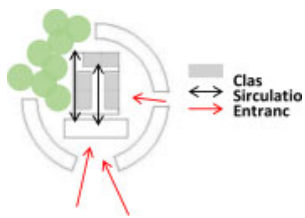

Figure 7. Sketch layout in Case.

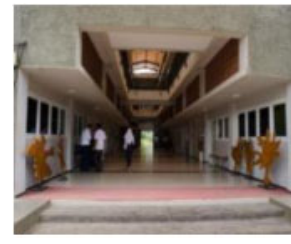

Figure 4. Corridor situation of Case A.

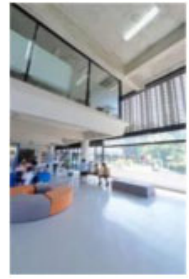

Figure 6. Circulation situation in Case.

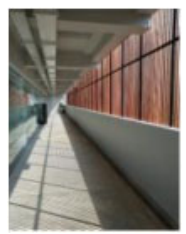

Figure 8. Circulation layout in Case.

Table 2. Circulation application design in every case.

\begin{tabular}{lll}
\hline Junior High School & Spatial Organization & Horizontal Circulations \\
\hline A & Linear & Double-Loaded \\
B & Radial & Double-Loaded \\
C & Radial & Single-Loaded \\
& & Double-Loaded \\
\hline
\end{tabular}




\section{CONCLUSIONS}

Psychology and human behavior are two of the approaches in the design process of interior architecture that can be raised to achieve an agreement between human space, product design, and the user's subject. In a junior high school case study with users predominantly early adolescents, the characteristics of the early adolescents are a reference from the expected designation process. Broadly speaking, these three case studies have no problem in the extent of circulation in the lobby and corridor areas with an average area of $6 \mathrm{~m}$. Here is the conclusion of the analysis obtained.

Radial space organization can be the main choice in the design of junior high schools, considering the characteristics of early adolescents who need space and gathering areas for students in an area that can be wider and more spread out. Linear organization with a corridor area according to the standard can lead the building users to not move in the corridor, so users will prefer other open spaces or in class double-loaded circulation is a type of circulation that is commonly used and based on space efficiency factors and site design limitations, these conditions can be optimized with a good design, supported by other space-forming elements, and also a single-loaded circulation. Good planning is planning that has a basic approach that is appropriate for the main user, taking into account the psychological and physical comfort of the user of the building.

\section{ACKNOWLEDGMENTS}

This paper was a research continuation from Telkom University Student Final Project: Redesign of Interior Space Edu Global School Junior High School Building in Bandung, a graduate requirement from Telkom University. This research wouldn't been possible without data provided from each Junior High School.

\section{REFERENCES}

Adler, D. 1979. New Metric Handbook. Grate Britain: Hartnolls Ltd.

Caudil, W.W. 1978. Architecture and You: How to Experience and Enjoy Building.

Ching, Francis, D.K. 2007 Architecture: Form, Space, and Order Volume 3. Jakarta. Erlangga.

Neufert, P. 2000. Architects Data Third Edition. Oxford: Blackwell Science.

Nurafni, Syfa. 2019. Proses Perancangan Ulang Interior SMP International Edu Global School Bandung. Telkom University.

Salura. P. 2001. Berarsitektur, Membuat, Menggunakan, Mengalami dan Memahami Arsitektur. Architecture Communication: Bandung.

Santrock, J. 2013. Childhood Development. 14th Edition, New York: McGraw-Hill Education. http://bekasi. binus.sch.id/facilities/ accessed May $2020 \mathrm{http} / /$ www.sekolahmutiarabunda.com/smp-mutiara-bunda-1 accessed May 2020. 